\title{
La Recopilación de 1641 de las Constituciones, Estatutos y Costumbres guardadas en la Pitancería de la Santa Iglesia de Cuenca
}

\author{
The Compilation of 1641 of the Constitutions, Statutes and \\ Customs stored in the Pitancería of the Holy Church of \\ Cuenca
}

\author{
Eulogio Fernández Carrasco ${ }^{1}$ \\ Universidad Nacional de Educación a Distancia. UNED. España. \\ cuencajucar@gmail.com
}

Recepción: 30.12.2016 Revisión: 05.01.2017 Aceptación:05.01.2017 Publicación: 15.01.2017

\section{Resumen (máximo 300 palabras)}

En el año 1637 el obispo de Cuenca, Enrique Pimentel, creyendo que era necesario se imprimiesen y se juntasen en un libro, las reglas, ceremonias y costumbres loables que se habían usado y usaban en el Coro, Cabildo y Procesiones de la santa Iglesia en Cuenca ordena que una vez estén recopiladas y una vez impresas, se dieran a todos los Prebendados y Beneficiados del Cabildo de Cuenca para su observancia y debido cumplimiento bajo la pena determinada en ellas en caso de incumplimiento a tenor de lo contenido en el libro de autos capitulares guardados en los archivos de la Iglesia de Cuenca. En 1638, el citado obispo, lo firma el 10 de marzo de 1638, dando fe de ello el Notario-Secretario Alonso López de Soria.

Palabras clave: Pitanza $^{2}$, Recles $^{3}$, More solito ${ }^{4}$, infiteusis ${ }^{5}$, recopilación.

\section{Abstract (maximun 300 words)}

\footnotetext{
1 Profesor Contratado Doctor de Historia del Derecho y de las Instituciones. Investigador en el Master Universitario en Protocolo de la Uned. Miembro del Grupo de Investigación: Historia del Pensamiento JurídicoPolítico en la Uned. Miembro del Instituto de Historia de la Intolerancia dentro de la Academia de Jurisprudencia y Legislación. Miembro colaborador de la revista Anuario de Historia del Derecho Español.

2 Pitanza: Distribución que se hace diariamente de algo, ya sea comestible o pecuniario. También: Ración de comida que se distribuye a quienes viven en comunidad. Igualmente significa la distribución que se hace diariamente de alimento, dinero u otra cosa.

Pitancero: El que reparte las pitanzas. En algunas iglesias catedrales, ministro que cuidaba de apuntar o avisar las faltas en el coro.

${ }^{3}$ Tiempo que se permite a los prebendados no asistir al coro para su descanso y recreación.

${ }^{4}$ Significa según el uso habitual. Se utiliza normalmente para indicar la acción repetida o que se repita de forma normal y habitual. Como de costumbre, como de costumbre.

${ }^{5}$ Cesión perpetua o a largo plazo del derecho a disfrutar de un inmueble a cambio de un pago anual.
} 
In 1637, the bishop of Cuenca, Enrique Pimentel, believed that it was necessary to print and put together in a book, the laudable rules, ceremonies and customs that had been used and used in the Choir, Cabildo and Processions of the Holy Church in Cuenca orders that once they are compiled and once printed, all the Prebendados and Beneficiados of the Cabildo de Cuenca will be given for their compliance and due compliance under the penalty determined in them in case of default according to what is contained in the car book Capitulares kept in the archives of the Church of Cuenca. In 1638, the aforementioned bishop signed it on March 10, 1638, and the Notary-Secretary Alonso López de Soria testified.

Keywords: Pitanza, Recles, More solito, infiteusis, compilation

\section{Sumario}

1. Introducción

2. Residencia anual.

3. Pan.

4. Vestuario y Semestre.

5. La Maitinada.

6. Pitanzas.

7. Manuales de las Procesiones.

8. Infiteosis.

9. More solito.

10. Recles.

11. Conclusiones

12. Bibliografía

\section{Summary}

1. Introduction

2. Annual residence.

3. Pan.

4. Clothing and Semester.

5. The Maitinada.

6. Pitanzas.

7. Manuals of Processions.

8. Infarthosis.

9. More alone.

10. Recles.

11. Conclusion

12. Bibliography

\section{INTRODUCCIÓN}


En relación a la localización del material de nuestro objeto de estudio ${ }^{6}$, hay que hacer notar, que dentro de los trabajos que versan sobre las Recopilaciones eclesiásticas del siglo XVII, no consta en la actualidad una monografía, sino sólo referencias, que aborden el examen que se hace aquí. Para el estudio de este trabajo, hemos estudiado en los manuscritos existentes en la Biblioteca Nacional.

El Obispo Enrique Pimentel da Comisión a Pedro Zapata y al Dr. Diego Ortiz de Zayas, Canónigos ambos, el día 2 de abril de 1637 para reunir en un solo libro, las reglas, ceremonias y costumbres loables que se habían usado y usaban en el Coro, Cabildo y Procesiones de la Santa Iglesia en Cuenca e hicieran relación de ello al Cabildo. Se da al Dr. Antonio Payno, Canónigo Magistral de Lectura, para que las lleve una vez recopiladas a Enrique Pimentel (obispo) y así obtener licencia y poder así imprimirlas. Una vez hecho esto, de deberían dar a cada uno de los Prebendados y Beneficiados, para que éstos, las usaran y cumplieran sin réplica ni contradicción, bajo las penas puestas en ellas, según constaba en los autos capitulares. Dicho libro o recopilación, se guardó en los archivos de la Catedral. El Notario y Secretario Antonio López de Soria, dio fe del libro el día 10 de abril de-1638 y nos dice que se lo entregaron los claveros y archiveros para tomar razón de lo referido. Enrique Pimentel obispo y del Consejo de Estado de su Majestad las aprueba en 28 hojas, el día 2 de octubre de 1641. Y da testimonio de lo ordenado por el obispo, el Licenciado Juan de Jaray.

Como introducción al tema que vamos a desarrollar, se tiene por cierto que la primera regla legal en lo concerniente a la Santa Iglesia de Cuenca respecto a los Estatutos que regulaban los extremos que a continuación se desarrollan, provienen de los estatutuos que concedió el Obispo San Julián al Cabildo catedralicio conquense en el año 1201, para la reglamentación beneficial. También se tienen noticias de los estatutos dados por el obispo Mateo Reinal y el Cabildo catedralicio en el año 1250. Por otro lado se tiene noticia que el 15 de junio de 1406 el también obispo Juan Cabeza ratificaría los estatutos dados por elo bispo citado anteriormente. También los Estatutos dados por Lope de Barrientos el 4 de octubre de 1445. El de 1487 de Fonseca.

\section{RESIDENCIA ANUAL}

\section{FORMA DE HACER LA RESIDENCIA ANUAL.}

Las Dignidades ${ }^{7}$, Canónigos ${ }^{8}$ y los Racioneros enteros ${ }^{9}$ que nuevamente fuesen a residir en Cuenca, estaban obligados a hacer una residencia anual por razón de sus canonicato y

\footnotetext{
${ }^{6}$ En relación a este trabajo, puede verse:

Regla del Coro y Cabildo de la Santa Iglesia Metropolitana de Sevilla y Memoria de las procesiones y manuales que son a cargo de los señores Dean y Cabildo de ella, de fecha 22 de enero de 1616, reimpresa en Sevilla el 19 de enero de 1658 por Juan Gómez de Blas, impresor de los señores Dean y Cabildo de la Iglesia Metropolitana de Sevilla. Especialmente pp. 119 y siguientes.

Regla del Coro y Cabildo de la Sancta Iglesia Cathedral de Cuenca. Cuenca. Viader, Salvador. 1641

BN. M/802

Estatutos del Excmo. Cabildo CatedraL de Madrid. Ceremonial y Regla de Coro y Gobierno de la Santa Iglesia Catedral Basílica de Madrid. Estatutos del Excmo. Cabildo Catedral de Madrid. Ipt. Dos de Mayo. MADRID 1953. Es un facsimil de la edición de 1892.

${ }^{7}$ Formaban el escalafón más alto del Cabildo. Eran: Deán, Arcediano de Cuenca, Arcediano de Huete, Arcediano de Alarcón, Arcediano de Cañete-Moya, Chantre, Tesorero, Maestrescuela, Abad de Santiago, Abad de la Sey, Arciprestazgo, Priorato, Capellán mayor
} 
Ración. Y ésta la podían comenzar cuando quisiesen, con que el señor Canónigo la haya de comenzar para ganar el vestuario, a las primeras Vísperas10 de San Miguel de septiembre.

Para ganar la dicha residencia había de ir cada día al Coro, con su hábito y estar en una de las siete horas Canónicas y ganar la hora, advirtiendo que en Maitines11, no se ganaba residencia por decirse el día antes; pero en los Maitines de Navidad y de la Resurrección sí, por decirse en el mismo día.

No tenía obligación de dormir el año de la residencia ninguna noche fuera de los muros de la ciudad de Cuenca, ni estar paseándose fuera de dichos muros después de las 12 de la noche, y en el caso de haber caído en algo de esto, perdía la residencia y todo lo que había ganado, y vuelvía de nuevo a comenzarla.

El medio Racionero ${ }^{12}$ no estaba obligado a hacer la residencia anual, pero si quisiese la podría hacer, y le valdría para no volver hacerla si tuviese Ración13 entera, Canónicato14, o Dignidad.

Ningún Canónigo podía ganar su vestuario ni otra cosa. Tampoco el Dignidad, ni el Racionero entero, el pan y pitanza de sus raciones, hasta haber hecho la residencia anual si expresamente por todos los Canónigos, no les fuese concedida la gracia de la residencia.

Al que estando en residencia le fuese dada por el Cabildo15 licencia para irse a ordenar o curar fuera de Cuenca, se le había de poner en el libro para ganar la dicha residencia, sin interrumpirla y ganar aquellos días que llevarse de licencia, pan, pitanzas y no otra cosa alguna.

Para comenzar la residencia, hacía falta pedírselo al Pitancero ${ }^{16}$ delante de tres testigos, y estando comenzada, o para comenzar la hora, tenía que estar el Pitancero en la Pitancería puesto.

\footnotetext{
${ }^{8}$ Las funciones administrativas del Cabildo de Canónigos se recogían en vários estatutos que estaban bajo la jurisdicción episcopal, donde se ordenaba el servicio litúrgico de la catedral y se determinaba la organización interna de dicho colectivo. Había 26 canonjías em la catedral conquense, uma de ellas, servida por el Tribunal del Santo Oficio.

${ }^{9}$ Los racioneros formaban el escalafón inferior del cabildo catedralicio. Su número era de 10. Su función consistia en auxiliar al cabildo de canónigos, tanto em el culto, como em la administración catedralicia.

10 Oficio religioso diario del clero católico, posterior a la nona y anterior a completas, que se celebra al anochecer.

11 Primero de los oficios religiosos diarios del clero católico, anterior a laudes, que se celebra antes del amanecer.

12 Los Medio racioneros formaban el escalafón inferior del cabildo catedralicio. Su número era de 12 . Su función consistia en auxiliar al cabildo de canónigos, tanto em el culto, como em la administración catedralicia.

${ }^{13}$ Prebenda en alguna iglesia catedral o colegial, y que tiene su renta en la mesa del cabildo.

${ }^{14}$ Canonjía (prebenda de la Iglesia).

${ }^{15}$ El Cabildo está formado por los Canónigos, sacerdotes elegidos por el Obispo para dirigir y administrar la S.I. Catedral. Se reúnen periódicamente en la celebración de los Capítulos donde se toman decisiones de manera colegiada por medio del voto. El presidente del Cabildo recibe el nombre de Deán y es elegido por los Canónigos durante un tiempo limitado.

${ }^{16}$ Pitancero era el oficial (generalmente era un Canónigo o Racionero) que controlaba las asistencias de los Capitulares en las horas del oficio, cobrando estos últimos ciertas cantidades de maravedíes no muy grandes,
} 


\section{PAN}

\section{GANA EL PAN DE LA RACIÓN, EL BENEFICIADO17 VIVIENDO}

Viviendo los Beneficiados, tenían obligación de residir desde las primeras Vísperas o el día de San Miguel de septiembre, hasta otro día de San Miguel de septiembre siguiente, cuatro meses continuos o interpolados sin poderse valerse en ellos de recles, para poder ganar el dicho pan.

\section{EN QUE CASOS SE PIERDE EL PAN}

El que no residiese a las primeras Vísperas de San Miguel de septiembre, o en una de las horas canónicas, de los ocho días después de dicho San Miguel, perdían el pan y pitanza que se llamaba con cola, hasta que fuese a residir, y en este caso no se puede aprovechar de recles y lo mismo son ocho días después de Año Nuevo en lo que toca al pan, ya que las pitanzas las perdía desde el día de Año Nuevo.

El que no residiese cuatro meses al año continuo o interpolado, estando viviendo, no ganaba más del tiempo que residía.

El excomulgado, suspenso, o entredicho, o echado, o multado por otra cosa, no ganaba por todo aquel tiempo que lo estuviese pan ni pitanza, si excedía de tres días, el cual perdía desde el día que se le echase del libro, e igualmente sucedía com los demás que faltasen a rata.

El que se ausentase, sin dejar casa abierta y pedir more solito ante el Pitancero, pasados ocho días, perdía pan y pitanza e igualmente los demás hasta que fuesen a residir.

El que permutase o resignase, había de ratear con el sucesor que entrase, según lo que cada uno residiese em esse año, y en este caso, aunque tenga hecho el semestre, el que resignase o permutase, no le valía, por servir solo, al que retenía su beneficio de un San Miguel a otro.

El pan de las raciones de los Beneficiados de la Santa Iglesia Catedral de Cuenca, vacantes, y que la víspera de San Miguel no entrasen a residir por el día, el pan que iban perdiendo, acrecía la masa de la Ración, hasta que comenzaba a residir.

El que entraba por resignación, permuta u otro cualquier título, no ganaba pan hasta que comienzaba a residir y continaba la residência. El medio Racionero que comenzaba a residir la iba ganado.

estando presente él. Lo hacía en un libro. Este libro se conocía con el nombre de Libro de Pitancería, generalmente un libro por año y cada libro estaba dividido en los 12 meses del año y éstos divididos en días, comenzando el día 1 de enero.

${ }^{17}$ El beneficiado o beneficiario es la persona que posee derecho a disfrutar del beneficio o rentas eclesiásticas y tiene la obligación de ejercerlo. Las rentas provenían de impuestos religiosos como los diezmos y las primicias o en cobros por el ejercicio del culto. 


\section{PAN QUE DEJABA GANADO EL QUE MORÍA}

Cualquier Dignidad, Canónico y el Racionero entero que habiendo hecho su residencia anual, y el medio Racionero que no tenía obligación de hacerla, después de 100 días que hubiese residido por el primer año, habiendo estado a una de las siete horas Canónicas, desde las primeras Vísperas de San Miguel de septiembre hasta otro Miguel de septiembre inclusive. Si moría dejaba ganado el pan de su ración, o media, si desde la hora que comenzó a residir, pudo hacer el semestre de los cuatro meses hasta el dicho día de San Miguel siguiente.

Adviértase que se entendía esto con quien no hubiese faltado en algunos días de pérdida de pan, como era, habiendo faltado de ir al coro ocho días, sin haber pedido moresolito, o que los hubieran puestoen los estatutos, por excomunión u otra cosa, que en tal caso, los que hubiesen perdido se les daba de baja. Respecto a los demás, sí se les daba.

\section{VESTUARIO Y SEMESTRE}

\section{COMO SE GANABA EL VESTUARIO Y EL SEMESTRE}

Cualquier Canónigo Prebendado que habiendo hecho su residencia anual, residiese en dicha iglesia 140 días continuos o interpolados, en cada año, el cual comenzaba desde las primeras Vísperas de San Miguel de septiembre, hasta Nona de la víspera de San Miguel de septiembre del año siguiente, estando en cada uno de los 140 días, a una de las siete horas canónicas, ganaba su vestuario.

Cumplía con comenzar su semestre de los 140 días, el día que quisiese pasado el día de San Miguel de septiembre, con tal que hubiese ya acabado dicho semestre, antes de las primeras Vísperas de San Miguel de septiembre siguiente. En Maitines no se ganaba semestre, si no era en los de la Navidad y Resurrección.

\section{MOTIVOS DEL POR QUÉ SE PERDÍA EL SEMESTRE}

El Canónigo Prebendado que no hiciese su semestre de los 140 días desde el día de San Miguel de septiembre hasta otro San Miguel de septiembre siguiente.

El que no habiendo estado la víspera, ni el día de San Miguel, ni muchos días después, de suerte que no fuese a residir en la iglesia hasta el 11 de mayo inclusive, no pierde, pero si pasa de este tiempo, pierde el vestuario, no por haber días en que hacer el semestre, sino por hhabía de acabarlo antes de las primeras vísperas de San Miguel donde se commenzaba a ganar el otro siguiente.

El que estando en residencia faltase algún día de ir al coro, a ganar una hora y asistir a ella con su hábito, o durmiese fuera de los muros de la ciudad, perdía el vestuario.

El que fuese nuevamente a residir, había de comenzar su residencia anual, antes de San Miguel, o por lo menos a las primeras Vísperas de él y así ganar el vestuario, y si no lo perdía.

El que resignase o permutase o fuese promovido a otro Canonicato de la Santa Iglesia Catedral de Cuenca u obispado y antes de acabar de hacer el semestre, se pasasen las bulas 
en Roma. Igualmente cuando en Cuenca proveyéndole el señor Obispo y Cabildo, tomase la colación y posesión, perdía el vestuario.

\section{DEJABA GANADO EL VESTUARIO EL QUE MORÍA}

Cualquier Canónigo Prebendado que hubiese hecho su residencia anual y hubiese estado en las vísperas primeras de San Miguel de septiembre donde se comienza a ganar el vestuario, o cualquier otro día después de pasado el día de San Miguel que hubiese entrado en la dicha iglesia Catedral a residir y hubiese ganado una de las siete horas Canónicas en el dicho día de San Miguel o en otro cualquiera muriese, ganaba y se llevaba enteramente el dicho vestuario del año próximo venidero, sin embargo, el sucesor no se llevaba nada.

Si fuese el 11 de mayo y comenzase su semestre, como tuviera días en que acabarle, si muriese, dejaba ganado el vestuario.

\section{LA MAITINADA}

\section{LA MAITINADA. COMO SE PERDÍA O SE GANABA}

Para ganar la Maitinada se requería verdadera y personal asistencia en el coro, de tal manera que si un beneficiado estando en mítines y habiendo ganado el preocupemus le daba algún mal, del que no pudiese volver a ganar el Benedicamus, aunque se excusase por enfermo, no lo ganaba, y así por esta razón no las ganaban los enfermos.

Para ganar los Maitines, no valía la excusa de necesidad corporal, ni otra, por haber de estar personalmente en el coro, con hábito, al preocupemus y al Benedicamus Domino.

En las Misas y Aniversarios, que son Maitinada, no se admite para ganarlas escusa ninguna si no es por necesidad corporal por haberlo así interpretado la costumbre.

\section{QUIEN LO GANABA TODO SINO ERA LA MAITINADA}

El Beneficiado a quien el Cabildo encomendaba algún negocio dentro o fuera de Cuenca.

El que había de predicar dentro o fuera de la Iglesia en la ciudad de Cuenca el día que predicase.

Los dos Canónigos Magistrales, el de Escritura y el de Penitenciaría, en las horas que leían. El Penitenciario cuando era llamado para confesar.

El Canónigo Doctoral, excusándose por los negocios y pleitos del Cabildo.

Los que estando en Cuenca se escusasen por enfermos y los que enfermasen fuera cuando el Cabildo mandase que se pusieran en el libro. 
Los medios Racioneros a quien el Cabildo daba licencia para ir a estudiar a alguna Universidad por razón del estatuto que había.

Los enfermos a quien el Cabildo diese licencia para salir de casa, sin perder la excusa de enfermos.

Todos los Beneficiados que fuesen al Coro a residir en las horas Canónicas.

Los que eran Inquisidores, o del Consejo Supremo, Fiscales o Secretarios.

Los que tuviesen Breve del Papa para hacerles presentes, por causa de estudio u otra cosa.

Los señores Canónigos capitulares que los días de Cabildo asistían en él.

Los Canónigos diputados de negocios u otra cualquier diputación o comisión del Cabildo, el Deán, su Teniente o Presidente siempre que se excusasen por él, estando en la Iglesia por negocios de ella.

Los Beneficiados que estuviesen presos, cautivos, desterrados o de cualquier modo impedidos, tenían la obligación de ir a excusarse a la Pitancería para poder ganarla.

Al señor Canónigo que fuese obrero, excusándose por la fábrica, y el limosnero por la limosna.

\section{PITANZAS}

\section{QUIEN GANABA PAN Y PITANZAS SOLAMENTE}

Al Canónigo o al Beneficiado que había de predicar en la Catedral, se le daban ocho días antes para que estudiase el sermón.

Los que se excusasen por quitarse la barba y cabello, que había de ser de 15 a 15 días y no en domingo, ni fiesta de guardar y había de ser por la mañana o tarde cuando se excusase.

Los que se excusasen por boda de hermanos, sería la mañana que se celebrase con licencia del Dean o Presidente.

Los que pedían licencia para ir a confesar fuera de la Iglesia, para cumplir con ella, o en tiempo de Jubileo plenísimo.

Los Beneficiados a quien llamaba la Inquisición para que acerca de alguna cosa tocante al Santo Oficio dijeran sus explicaciones.

El que hacía alguna obra casera de la Iglesia que tenía a su posta, siendo el gasto por cuenta de ella, habiendo estado primero en Prima y pidiendo licencia al que presidía, le contaban todo el día.

El Canónigo que fuese Provisor en sede vacante. 
A los que el Cabildo daba licencia por causa de voto o peregrinación.

Al Beneficiado que fuese al entierro de padre, madre o hermanos, se le daba el día del entierro y los tres días siguientes.

Al Beneficiado que fuesen testamentarios de otros Beneficiados de la Iglesia, el día del entierro.

A las señores Dignidades y a los Racioneros enteros, a quien el Cabildo daba licencia para ir a estudiar a alguna Universidad, por el estatuto que tenían, se les hace presente en la mitad de las pitanzas y superávit y en el pan de su Ración.

Los Beneficiados que habiendo pedido recreación al Cabildo por causa de enfermedad, durmiendo dentro de los muros de la ciudad, si no se daba para fuera de Cuenca.

A los que conforme a los estatutos salían a defender su Prebenda o Beneficio que tenía en esa Iglesia estando poseyéndolos de forma quieta y pacífica.

Los Beneficiados que acompañaban al Obispo en la visita del Obispado o en otra jornada, con licencia del Cabildo.

Al Beneficiado a quien el Cabildo hubiese dado recreación para ganar pan y pitanza, si quisiese ganar manuales, había de renunciar a la dicha licencia de recreación ante el Pitancero, y no podía tornar a gozar la citada licencia, si no se le concedía de nuevo; pero si quisiese ir a las horas gozando de la recreación, podía, pero no ganar manuales.

\section{QUE GANABAN LOS CANÓNIGOS CUANDO IBAN A ESTUDIAR}

A los Canónigos, Prebendados a quien el Cabildo daba licencia, por razón del Estatuto para ir a estudiar, se les hacía presentes en todo el pan de la ración, vestuario y semestre y no ganaban otra cosa el tiempo que estaban en la Universidad estudiando.

\section{QUÉ PITANZAS PERDIDAS SE REDIMEN CON RECLES}

Los Beneficiados que estaban puestos en la margen del libro, por no haber ido a las horas.

Los que en sede vacantes salían por visitadores y salían a visitar el Obispado.

Los Canónigos Prebendados y Examinadores Sinodiales, al tiempo que asistían al examen de los Beneficios, faltando de las horas

Los que se ausentaban de Cuenca sin pedir more solito y fuesen a residir antes que pasasen ocho días.

\section{PITANZAS PERDIDAS QUE NO SE REDIMÍAN CON RECLES}

Todas las pitanzas que los estatutos y constituciones mandaban que se quitasen así de horas como de días. 
Las pitanzas que fuesen quitadas por el Cabildo y las que el Deán o Presidente quitasen, por faltar en lo que se les ordenasen.

El que estaba en recesit por el Cabildo, excomulgado, suspenso o por el estado de las palabras contumaces e injuriosas, no podían entrar en la iglesia con hábito.

A los que les fuesen encomendadas Capas, Responsos, Lecciones o Benedicamus y no obedeciesen a los que se lo encomendasen.

Los Beneficiados que faltasen a las Procesiones de estaciones de tarde y Antífonas de las Oes, Vísperas y Misa de finados.

Los que se pasasen por la Iglesia con hábito o sin él diciéndose las horas o negociasen con otro aunque hubiesen perdido la hora en que se paseaban, como consecuencia, se le había de quitar la otra hora próxima que ganase.

Cualquier Dignidad, Canónigo y el Racionero y medio que el Miércoles de Ceniza no se hallase en el Cabildo a la venia estando en Cuenca, no estando enfermo, tenía tres días de pérdida.

Los Beneficiados que los Domingos y fiestas de guardar, estando en Cuenca no fuesen a la procesión no estando enfermos.

El Beneficiado que diciéndose las horas o sermón fuese a la Iglesia sin hábito, sino fuera de passo, decir Misa, oírla o alguna Comisión del Cabildo, aunque estuviese en el coro su coadjutor.

El Preste y Diáconos si no estuviesen a tiempo vestidos para salir a decir la Misa, de suerte que no aguardase el coro.

El que estándose en su silla, diciéndose las horas pasase de un coro a otro, si no es con licencia del que preside o se quedasen en las sillas bajas o Pitancería.

El Beneficiado que tomase o dejase la Capa que llevan en las procesiones solemnes, si no fuese dentro del coro.

El que tomase la capa de otro Beneficiado que viniese.

El que se ausentase en tiempo de cesación a divinis sin licencia del Cabildo.

El enfermo que estando excusado por tal, saliese de su casa antes del tiempo que se le permitese o saliese sin ir primero a la Iglesia si no tuviese licencia de recreación. El que se excusase por la mañana a Prima podía salir otro día a la misma hora. Pero si se excusase a Tercia u otra cualquier hora, no podía salir hasta el tercer día. Si lo hacía tenía tres días de pena de lo ganado.

El que estando en Cabildo saliese de él mientras las horas sin licencia del que presidía. 
El Beneficiado que entrase en el coro mientras las horas sin el hábito de él, conforme al tiempo.

\section{MANUALES DE PROCESIONES}

\section{COMO SE PERDÍAN LOS MANUALES DE LAS PROCESIONES Y EN DIAS DE OFRENDA}

Todas las procesiones de Capas, solemnes y de estaciones, como de Letanías, Rogaciones y otras generales que se hacían fuera de la iglesia, habían de entrar los Beneficiados en ellas antes que acabasen de salir de entre los dos coros, las dos últimas Dignidades y el que no entrase en este tiempo, perdía los manuales.

En los días que había ofrenda de los Beneficiados en el Altar mayor, si faltaban a la ofrenda, perdían los manuales y por ninguna excusa se podían excusar, sino era por necesidad corporal.

\section{INFITEOSIS}

\section{GANAR INFITEOSIS}

Todos los Beneficiados que se hallasen en los días de Cabildo ordinario en el coro por la mañana, o en el Cabildo, ganaban los initeosis.

Igualmente todos los que se hallasen en la ciudad por la mañana los días de Cabildo extraordinário, ganaban dichos infiteosis.

\section{MORE SOLITO}

El que ostentase Dignidad o fuera Canónigo y el Racionero entero, habiendo hecho su residencia anual y quisiese salir de Cuenca, debía pedir licencia More solito ante el Pitancero por su misma persona y no por otra, ni por escrito, porque de otra manera, pasados ocho días perdía con cola pan y pitanzas.

El que tenía licencia del Cabildo estando en negocios de la Iglesia u otro cualquiera por tiempo limitado o no, cuando salía al tal negocio, debía pedir licencia More solito al Pitancero, para que en acabando el negocio, no importando que en este caso el negocio durase un año o dos, para pedirselo acabando el negocio, porque sin esto y acabado el negocio, y el tiempo que se le daba para volver perdería con cola.

El que pedía More solito y después de pedido no usase de él pasados ocho días no le valía aunque lo pidiese condicionalmente para cuando faltase, sino que le había de volver a pedirlo. Y adviértase que no le valía el More solicitado de un año para otro, como tampoco valían los recles, excepto el More solito que pide el que salía a los negocios de la Iglesia, o llevaba licencia del Cabildo por alguna causa.

COMO SE USA DEL MORE SOLITO 
El More solito para no perder pan y pitanzas se pedía dos veces al año, la una había de ser desde el día de San Miguel de septiembre, habiendo asistido en el coro y ganando alguna hora canónica o en aquellos ocho días siguientes. El cual valía hasta la víspera del Año Nuevo.

La otra había de ser forzosamente el día de Año Nuevo, para no perder pitanzas y habiendo estado en el coro alguna hora canónica aquel día, que no se podían tomar recles sin esto por comenzarse a gozar de ellos desde el principio del año, e iba perdiendo dichas pitanzas tan solo los días que faltaba hasta que entrase a residir; pero si pasaban ocho días, perdía con cola, y lo mismo era pasados ocho días de San Miguel en septiembre.

El que tenía licencia del Cabildo para ausentarse por algún tiempo, o el Cabildo le enviase por negocios suyos, podía pedir licencia Moresolito al Pitancero, para cuando se le acabase la citada licencia que llevaba o el negocio a que iba, de suerte que si el negocio se acabó después de San Miguel de septiembre, el More solito le valdría hasta la víspera de Año Nuevo, sin tener necesidad de ir a la Iglesia. Y si era después de Año Nuevo, le valía hasta la víspera de San Miguel. Y en estos dos casos, estaba platicado y guardado, no obstante que el More solito se acababa la vispera de San Miguel y la de Año Nuevo para los que no se ausentaban por las razones dichas.

Si algún Prebendado de esa santa iglesia tuviese coadjutor, estando en Cuenca ambos, no podia el propietario pedir More solito porque debía residir el coadjutor en su ausencia; pero si estando el propietario ausente, se hubiese de ausentar el coadjutor, en tal caso podría dicho coadjutor pedir el More solito para ausentarse. $Y$ adviértase que estando enfermo cualquiera de los dos, estando ambos en Cuenca, ninguno se podía excusar, sino que tenía que residir el que estuviese con salud, que de otra manera no se les sentaba en las horas.

Si el Cabildo daba licencia, o hacía presente a algún Beneficiado en alguna hora, el día de San Miguel, o el día de Año Nuevo, por ella se le concedia el que usase del More solito que tenía pedido y así no lo perdía, sino que gozaba de sus recles.

\section{RECLES}

\section{RECLES QUE CADA BENEFICIADO PODÍA TOMAR AL AÑO}

Podían cada año los Beneficiados gozar de 93 días de Recles, los cuales se habían de comenzar a tomar desde el día de Año Nuevo habiendo asistido a Prima, o a otra hora de aquel día. Adviértase que aunque no hubiese perdido después de Año Nuevo o de San Miguel, ocho, quince o más días, no por esto perdía los Recles que sólo perdía las pitanzas y el pan, ya que los Recles le quedaban enteros para tomarlos cuando quisiese, bien juntos o bien interpolados.

Se dividían estos 93 días en los 12 meses del año, que a cada uno de los tres meses tocaba a ocho días y a los otros tres a siete días y medio.

Un Recle entero era faltando todo el día y medio toda una mañana, o toda la tarde, de suerte que no yendo uno a Prima y yendo a Tercia y faltando a la Misa, Sexta o Nona, aunque hubiese dos, ni tres faltas de horas, no se computaba la pérdida más que por medio 
Recle, que es medio día, y las Vísperas de Cuaresma que se dicen por la mañana se cuentan con las demás horas.

El que permutaba o resignaba su Beneficio, o muriese, gozaba de los Recles hasta el día que muriese o se iba y su sucesor desde que comenzaba a residir, contando a cada uno los que por cada mes le tocaba de los 93 días por año a razón de ocho días la mitad de los meses, y a siete y medio la otra mitad, dando a cada uno con igualdad. Adviértase que los Recles se podían tomar juntos o interpolados, como cada uno quisiese.

\section{LOS RECLES QUE SE TOMABAN DE MÁS, COMO SE ACOMODABAN A MENOS PÉRDIDA}

Los Recles que se habían tomado de más de los que podían cada mes o año, se habían de acomodar en las horas que perdiese menos el Beneficiado. Verbi gracia, el Beneficiado que faltó a la Prima y perdió las Completas, rebajados los días que le tocaba en el mes o año de Recles, se le contaría como pérdida a las Completas.

Los que habían tomado algunos Recles de más de los 93 días, y perdían las Completas de Cuaresma, se les acomodaba a la pérdida en ellas, o en otra hora que menos pitanza tuviese, de suerte que fuese en lo que menos perdiesen cómo hubiesen faltado en aquellas.

Las horas para los Recles eran todas las que tienían pitanzas como Prima, Tercia, Sexta y Nona, Vísperas, Completas y Misa de prima, Aniversario de los lunes. La Misa Conventual. Aniversario de los cincuenta y tres. La Misa del Miércoles, Viernes y Sábado.

\section{CONCLUSIÓN}

La Recopilación de 1641 se articuló y concatenó para que continuamente se celebrasen en ella los divinos oficios, con uma gran devocion y con autoridad y modestia ejemplar para que aprendiendo de las personas que en ella asistían a celebralos toda compostura y atencion, en orden al aumento del culto divino, al igual que los demás del pueblo viesen en los Beneficiados como en espejos cristalinos, la reverencia con que habían de.estar en el Templo, y el silencio y mesura que han de guardar en la casa de Dios.

A través de este trabajo, descubrimos que la Recopilción religiosa se dedica a estudiar la importancia de la praxis litúrgica y la existencia de rituales religiosos, cómo se procedía en el funcionamiento de sus actos y la realización de sus ceremonias por ser la principal vía de manifestación y expresión de los métodos e instrucciones que intervienen en sus manifestaciones religiosas.

Sin embargo no podemos negar la evidencia de que son parciales e incompletos, debido a la escasez de los documentos que contienen las normas sobre su desarrollo en la documentación conservada; pero que sin embargo, nos enseñan y nos dan testimonio de la existencia de unas normas sobre actos religiosos, que como se comprueba con el paso del tiempo, las nuevas Recopilaciones, se limitan a recogerlas casi en su totalidad, aunque eso sí, adaptándolas a las transformaciones y exigencias de la Iglesia. La dificultad reside en la escasa y dispersa información existente; pero de cuyo análisis obtenemos la visión históricoartística de esta manifestación. 
El análisis de los documentos encontrados en la Biblioteca Nacional, nos enseña que el contexto era significativamente solemne y respetuoso en la ceremonia eucarística, donde se acumulan gestos de bienvenida y despedida durante el rito de la exposición de los dones para su ofrenda que son palabra del ofrecimiento de la Iglesia y se exponen juntos, el honor y el respeto por la regulación sobre determinados aspectos de la Pitancería

Con ello logramos el conocimiento detallado de los usos, costumbres, hábitos, prácticas y ceremonias del protocolo religioso, en definitiva, de sus componentes internos y externos y la gran significación y validez de sus símbolos y actos tanto en la vida religiosa.

\section{BIBLIOGRAFÍA}

CALLAHAM, W.J. (2002) La Iglesia católica en España (1875-2002). Barcelona. Editorial Crítica S.L.

CID, C.; RÍU, M.; CASTILLO, A. del. (1965) Historia de las Religiones. Editorial Ramón Sopena S.A.

CONTRERAS MAZARÍO, J. M. (2011). Marco jurídico del factor religioso en España. Madrid. Editorial Observatorio del Pluralismo Religioso en España.

DÍAZ BONILLA, M.A. (2003) Organización, ceremonial y protocolo en la Iglesia Católica. Madrid: Ediciones Protocolo.

ESCALERA AICUA, S. (2005). Ceremonial y protocolo religioso. Madrid: Ediciones Protocolo.

MARTINEZ DE ANTOÑANA, R.P. Gregorio. (1952) Manual de Liturgia Sagrada. Madrid. Editorial del Corazón

MORENO GONZÁLEZ, J.R (2011). Introducción al protocolo eclesiástico. Madrid: CEU Ediciones.

PARDO, A. (1998) Rituales de Los Sacramentos: Textos Litúrgicos Oficiales. Madrid. Biblioteca de autores cristianos.

SÁNCHEZ GONZÁLEZ, D. Del M. (2011). Fundamentos del Ceremonial y del Protocolo. Madrid: Editorial Síntesis.

SÁNCHEZ GONZÁLEZ, D. Del M. (coord.) (2012). Protocolo. Tradiciones, actualidad y crisis. Madrid: Sanz y Torres-UNED. 